\title{
The role of electricity mix and production efficiency improvements on greenhouse gas (GHG) emissions of building components and future refurbishment measures
}

\author{
Tajda Potrč Obrecht ${ }^{1}$ (1) $\cdot$ Sabina Jordan ${ }^{1} \cdot$ Andraž Legat $^{1} \cdot$ Alexander Passer $^{2}$
}

Received: 23 June 2020 / Accepted: 22 March 2021 / Published online: 6 May 2021

(c) The Author(s) 2021

\begin{abstract}
Purpose An estimation of the environmental impact of buildings by means of a life cycle assessment (LCA) raises uncertainty related to the parameters that are subject to major changes over longer time spans. The main aim of the present study is to evaluate the influence of modifications in the electricity mix and the production efficiency in the chosen reference year on the embodied impacts (i.e., greenhouse gas (GHG) emissions) of building materials and components and the possible impact of this on future refurbishment measures.

Methods A new LCA methodological approach was developed and implemented that can have a significant impact on the way in which existing buildings are assessed at the end of their service lives. The electricity mixes of different reference years were collected and assessed, and the main datasets and sub-datasets were modified according to the predefined substitution criteria. The influence of the electricity-mix modification and production efficiency were illustrated on a selected existing reference building, built in 1970. The relative contribution of the electricity mix to the embodied impact of the production phase was calculated for four different electricity mixes, with this comprising the electricity mix from 1970, the current electricity mix and two possible future electricity-mix scenarios for 2050. The residual value of the building was also estimated. Results and discussion In the case presented, the relative share of the electricity mix GHG emission towards the total value was as high as $20 \%$ for separate building components. If this electricity mix is replaced with an electricity mix having greater environmental emissions, the relative contribution of the electricity mix to the total emissions can be even higher. When, by contrast, the modified electricity mix is almost decarbonized, the relative contribution to the total emissions may well be reduced to a point where it becomes negligible. The modification of the electricity mix can also influence the residual value of a building. In the observed case, the differences due to different electricity mixes were in the range of $10 \%$.

Conclusions It was found that those parameters that are subject to a major change during the reference service period of the building should be treated dynamically in order to obtain reliable results. Future research is foreseen to provide additional knowledge concerning the influence of dynamic parameters on both the use phase and the end-of-life phase of buildings, and these findings will also be important when planning future refurbishment measures.
\end{abstract}

Keywords Global warming potential (GWP) Production phase $\cdot$ Electricity mix $\cdot$ Production efficiency $\cdot$ Residual value Refurbishment $\cdot$ Building components $\cdot$ Life cycle assessment (LCA)

\section{Introduction}

Communicated by Holger Wallbaum.

Tajda Potrč Obrecht

tajda.obrecht@zag.si

$\triangle$ Alexander Passer

alexander.passer@tugraz.at

Extended author information available on the last page of the article
Construction has been identified as one of the most important target sectors to be tackled in order to reduce climate change and its effects. This has been highlighted in the reports published by the UN Environment (UN Environment Programme 2018; UNEP 2020), the International Energy Agency (IEA and UNEP 2019), and the International Panel on Climate Change (IPCC 2018), among others (Wu et al. 2017). These reports have also indicated that buildings have 
significant potential for reducing their impacts on the environment when they are made fossil-free and with near-zero energy consumption within a short period of time (Röck et al. 2019). The regulations for new buildings are thus becoming ever stricter, but on the other hand, the majority of emissions are caused by buildings that are already in existence. Research has indicated that $80 \%$ of all buildings that will be occupied in 2050 already exist and must therefore be renovated as a priority in order to reduce their environmental impacts and mitigate climate change (Vilches et al. 2017). Refurbishment of the existing building stock has been recognized as one of the key future tasks for reducing the environmental impacts associated with buildings (Anand and Amor 2017; EC 2020).

Much research has been done recently on how to reduce the environmental impacts of the existing building stock with refurbishment measures (Häkkinen 2012; Ballarini et al. 2014; Assiego de Larriva et al. 2014; Oregi et al. 2015, 2017; Corrado and Ballarini 2016; Agostino et al. 2017). These studies mainly focus on investigating different refurbishment approaches and their influence on the environmental impacts of the buildings (Stazi et al. 2012; Pomponi et al. 2015; Ortiz et al. 2016; Passer et al. 2016; Ruud et al. 2016; Rodrigues et al. 2018). For the calculation of the environmental impacts the life cycle asessment (LCA) methodology is often applied. Assessing the environmental impacts of building refurbishment, however, has proved to be a challenging task. Vilches et al. (2017) identified one of the biggest problems are the different interpretations of EN 15978 and the different scopes of the studies. In his study, he emphasized that the environmental impacts of materials and components prior to the refurbishment should also be analysed if we are assessing the environmental impacts of the entire building (and not just the impacts of building-refurbishment measures) in order to avoid the information gap for the end-oflife (EoL) processes. Including the information about the processes and materials before the refurbishment also helps to determine the residual value of a building or a component correctly. Its correct determination supports the evaluation of the refurbishment in comparison with the alternative scenario "demolition and new construction." According to Severin (2018) and Guida et al. (2015), the residual value is the sum of the not-amortized environmental impacts embodied in building materials observed at a specific point in time. When observing a building at a specific point of time during its life cycle, some materials are already amortized and some still have a large residual impact, because either they have a long reference service life (RSL) or they were recently exchanged (Grant and Ries 2013; Grant et al. 2014; Rauf and Crawford 2015; Potrč Obrecht et al. 2019), as illustrated in Fig. 1. With the "residual-value" approach, we can obtain an insight into whether the materials have fulfilled their function (e.g., building component 2 ) or if their lifespan ended prematurely (e.g., building components 1 and 3). This information is important for planning future refurbishment measures and so it must be calculated correctly. Nevertheless, there is a lack of scientific literature dealing with the residual environmental impact of buildings and its effect on refurbishment decisions.

To calculate the residual embodied impacts (the residual value) of existing buildings, we need data for the construction materials that were manufactured in the past. However, at that time, no data about the environmental impacts for the production of individual building materials was collected. The first official life cycle inventory (LCI) databases started in the late 1990s, and no data is available before this period (Martínez-Rocamora et al. 2016). Although some processes might have changed over time, it is assumed that the general principles for the production of the building materials stayed the same for several decades, with the result that the current datasets can also be remodelled to obtain an approximation of the embodied environmental impacts of the materials produced at an earlier date. For a more accurate modelling of environmental emissions in the past, including the
Fig. 1 Residual value of a building (shaded grey) (Potrč Obrecht et al. 2019)

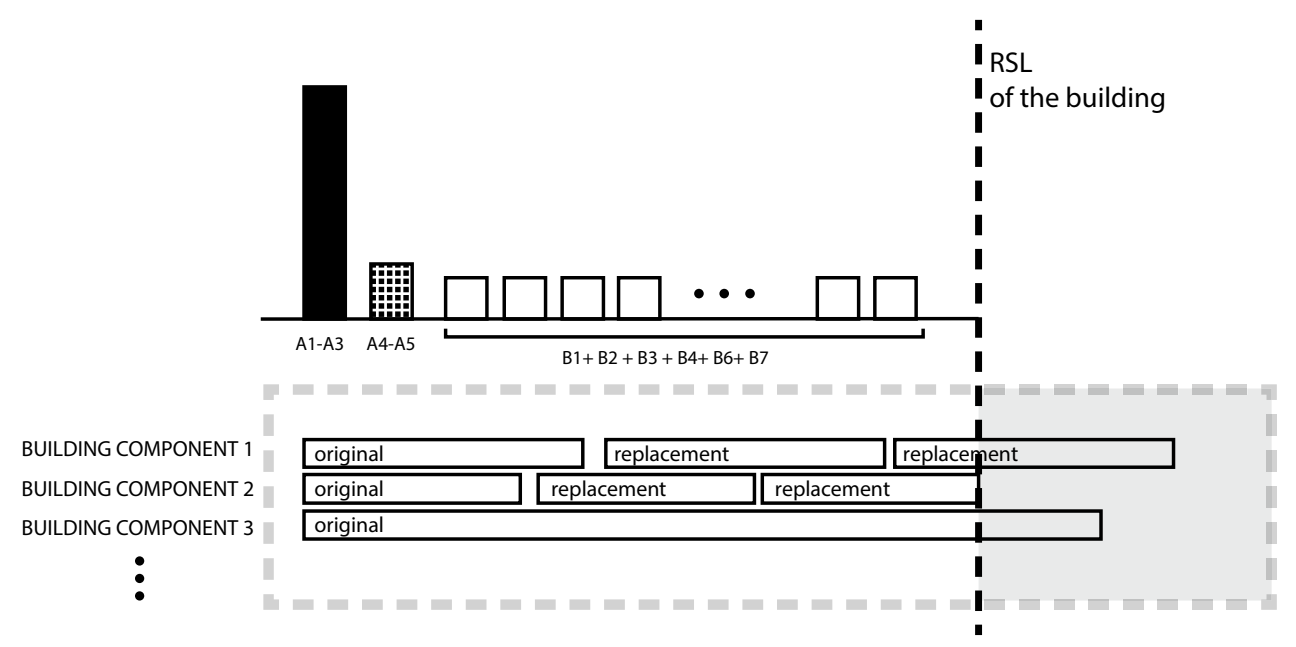


production change, accurate data is needed. However, this is often difficult to obtain.

In this study, we have shown the influence of the dynamic development of production on environmental impacts by using the example of the timely accurate electricity mix and assuming an increase in production efficiency over time. Following some principles of a dynamic LCA, which is an approach that includes dynamic process modelling in the context of temporal and spatial variations in the surrounding industrial and environmental systems (Collinge et al. 2013; Su et al. 2017), we can re-model the electricity mix in the already-existing LCA datasets (e.g., in databases like Ecoinvent) to correspond with the electricity mix used at the time of the production of the selected materials. The electricity mix is a combination of different sources and technologies of electricity generation that are constantly developing over time (Barros et al. 2020). The study of Kono et al. (2017) suggested that in some cases, it is even makes sense to use hourly greenhouse gas (GHG) emission factors to quantify the global warming potential (GWP) accurately. Studies have shown that the energy or electricity mix chosen in an LCA study usually has a strong influence on the LCA results, and due to the long lifespan of the building, the parameter is subjected to changes during this period (Roux et al. 2016; Barros et al. 2020). Therefore, the re-modelling of the datasets contributes to a more realistic determination of the environmental impacts produced in the past and thereby also to a more reliable determination of the residual value of the buildings. To the best of our knowledge, however, this issue has never been investigated in any previous research work and is a novel approach in this field.

The objective of the paper is to compare the environmental impacts of selected building materials and components that were modelled with the electricity mix and the assumed efficiency for the past. In addition, we also assessed the predicted future electricity mixes to test whether the relevance of using the accurate electricity mix will increase or decrease in the future. The LCI datasets were adapted in such a way that they give an approximation of the production procedure using the electricity mixes that were used at a specific time in the past. A case-study building located in central Europe (Slovenia) was selected to illustrate the approach. A temporal differentiation is introduced, which is not normally applied in a traditional LCA. The scenarios for the electricity mix and the production efficiency were based on the collected data and the assumptions.

Additionally, the extent to which the modification of the electricity mix and the production efficiency influence the residual value of the building was tested. The calculation of the residual value for the building is often used to determine the refurbishment measures and to observe which elements are discarded prematurely during the refurbishment process. The aim is to find out whether the modification of the electricity mix has a strong impact on the residual value of the building and its components and can therefore have an influence on decisions about the refurbishment measures.

\section{Methodology}

A new approach to the modelling was developed for the testing the objectives. The approach involves three phases, as presented in Fig. 2. In PHASE 1, the electricity mix is remodelled for the selected periods. This phase is explained in Sect. 2.1. In PHASE 2, the life cycle inventory datasets are remodelled using the electricity mixes obtained in the previous phase. At this point, cut-off criteria were applied to avoid the re-modelling of the submaterials that do not make a significant contribution to the end-results. The re-modelling process is presented in Sect. 2.2. In PHASE 3, the residual value of the building is calculated using the remodelled datasets. This phase is further explained in Sect. 2.3.

The results are presented for the GWP impact category. The database used in the study is Ecoinvent 3.5 (Werner et al. 2016). The characterization factors used for the calculation were CML 2001-January 2016 (Heijungs et al. 2013). The novel approach is illustrated for the case study of an apartment building in Slovenia, built in 1970, that is now to be renovated, and for which the residual value will first be calculated. The case study is a reference building, representing a typical residential building from the period between 1971 and 1980. It was selected as part of international project Tabula (Ballarini et al. 2014; Mastrucci et al.
Fig. 2 New, three-phase approach to re-modelling the existing datasets and calculating the residual value of a building with the time-corresponding electricity mixes (EM)

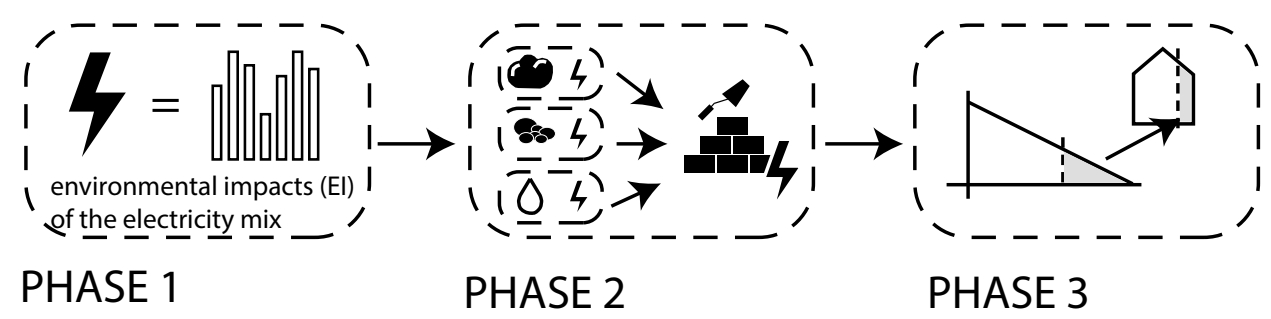

modelling of relevant EM changing the EM for the material and submaterials calculating the residual value of the building 


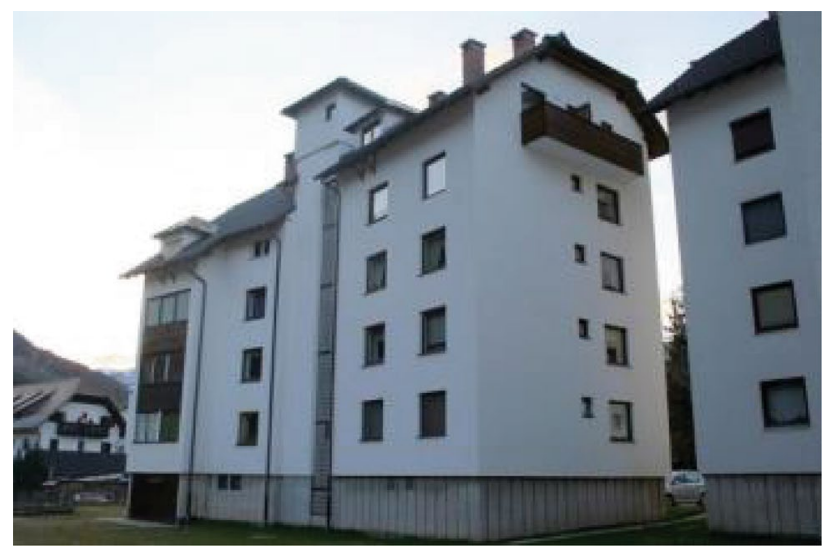

Fig. 3 Reference building, a typical residential building from the period 1971-1980

2017). The building is presented in Fig. 3 and Table 1. The scope of the study is focused on the embodied impact of the production phase, i.e., phases A1-A3, covering the rawmaterial supply, transport, and manufacturing according to EN 15,978 (CEN 2011). The functional unit (FU) is defined as the whole typical residential building, with a RSL of 60 years (Fořt et al. 2018).

\subsection{Electricity mix remodelling}

The electricity mixes of individual countries change continuously, in general following the national strategies and technological developments. For example, they must now comply with the global energy and climate targets set out in the European Green Deal strategy (EC 2020), the main goal of which is for Europe to become the first climateneutral continent, following the goals of the Paris Agreement (UN 2016). For this reason, the environmental emissions from the electricity mixes are in a constant state of change.

As a first step, the electricity mixes for the past were remodelled based on the data obtained from Slovenian's Statistical Office (SI-STAT), while the prediction for the future electricity mix was obtained from two sources: the

Table 1 Reference building, a typical residential building from the period 1971-1980

\begin{tabular}{ll}
\hline Reference building & \\
\hline Component & Area $\left(\mathrm{m}^{2}\right)$ \\
\hline Foundation slab & 506.5 \\
Outer wall & 1241.9 \\
Windows & 267.9 \\
Slabs & 2532.5 \\
Inner walls & 4216 \\
Roof & 646.6 \\
\hline
\end{tabular}

Energy Concept of Slovenia (ECS) (Slovenian Ministry of Infrastructure 2017) and the National Energy and Climate Plans (NECP) (European Commission 2020). The environmental emissions for the average electricity mixes in every decade between 1970 and 2050 were then calculated. The results of these calculations are shown in Fig. 4.

As presented in Fig. 4, Slovenia's electricity mix in 2020 is still heavily dependent on nuclear, thermal (coalgenerated), and hydro energy. Prior to 1970 , the year when the Slovenian nuclear power plant was built, the electricity requirement was supplied solely by hydro and thermal power plants. The long-term strategy, in line with international policies, is to decrease the use of fossil fuels and to increase the share of renewables and low-carbon energy sources.

In this paper, we present two possible future developments for the electricity mix. The first scenario, the ECS, makes the assumption that the nuclear power plant will be active until 2043 and that fossil fuels will have been abandoned by 2040 . The electricity supplied by these two sources will be replaced partly by renewable energy sources and partly by the use of natural gas. As shown in Fig. 4, in first period, the GHG emissions will decrease only slowly, because of the abundance of fossil fuels, while after 2040, emissions will increase, when the electricity from the nuclear plant is partly substituted by energy from natural gas, which typically has larger emissions. The second scenario, that of the NECPs, proposes a decarbonisation of the electricity mix by building a new nuclear power plant and increasing the share of renewable-electricity production. The GHG emissions will then be decreasing steadily during the observed period. However, we must emphasize that due to the electricity generation from nuclear power, the GHG emissions from the electricity mix will be decreasing. The use of nuclear power remains controversial but these problems exceed the scope of this study (Wang et al. 2019).

\subsection{Remodelling of the datasets}

In the second phase, some of the existing life cycle inventory (LCI) datasets of building materials were remodelled. The most common databases use the unit process (u-so) or the aggregated (agg) approach for modelling their datasets (Espinoza et al. 2000). The first of these make it possible to trace the processes down to the raw-material extraction and gives a very accurate insight into which processes contribute the most to the final environmental emissions. The downside of this is that the models are very large and difficult to manage. The agg databases, on the other hand, are small and very easy to use, but they do not provide a detailed insight into the upstream processes. Furthermore, they are unable to provide the option of being changed at any point, as most of 
Fig. 4 The composition of the energy mixes modified for the purposes of the study and the corresponding GHG emission results

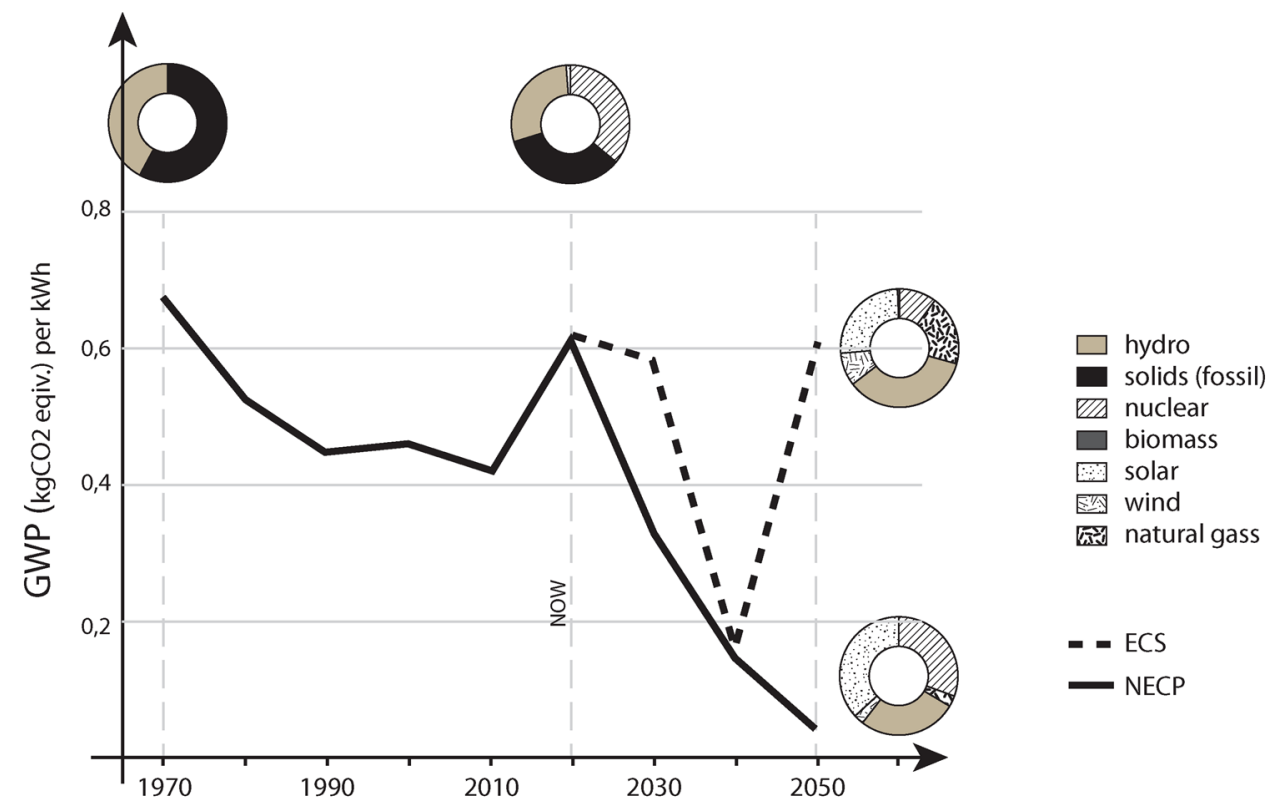

the data are accessible only to the database operators. Since the task of this phase is to remodel the datasets, the u-so dataset had to be used. Therefore, the Ecoinvent database 3.5 (Ecoinvent integrated in Gabi) was used in this study (Werner et al. 2016). Its database contains the u-so datasets that make possible the remodelling (Saade et al. 2019). The remodelling and calculating of the results were performed in Gabi.

The remodelling process is illustrated in Fig. 5. In STEP 1 the electricity mix of the original process dataset alone was replaced with the electricity mix of the period when the component/material was produced. We assumed that the country's electricity mix is representative, although we have to point out that in practice the component could be produced with a regional mix that is different, or that the component could be produced in other countries. However, this is beyond the scope of the study. In STEP 2, the electricity mix of the original processes dataset is further subdivided into subprocesses, and in each of the processes and sub-processes the electricity mix was replaced with the electricity mix of the period in which the component/material was produced. The third step (STEP 3) follows the principle of the previous two, but in addition, the production efficiency is modified. A $0.5 \%$ production efficiency increase in electricity consumption per year is assumed (as in Van De Moortel (2019)) since no actual data about the efficiency increase of individual production processes were found for the observed region. This means that the production process is assumed to have been less efficient in the past and thus required a higher electricity input. On the other hand, production in the future is expected to be even more efficient than at present and less energy will be needed. For the calculation of the efficiency increase, the interest rate methodology was applied using the equation:

$G \mathrm{n}=G 0+\mathrm{n} \cdot(G 0 \cdot p) / 10$

where $G_{o}$ are the initial impacts calculated for the current conditions, $p$ is the interest rates, and $n$ is the time horizon in years. The cut-off criteria were applied to remodel the existing datasets. The electricity mix was modified in those sub-materials that make up more than $1 \%$ of the entire mass of the initial material and that include the electricity mix as one of the inputs.

\subsection{Residual value calculation}

The residual value is the sum of the not-yet-amortized, embodied energy/environmental impacts evaluated in a
Fig. 5 Stepwise remodelling of the existing datasets

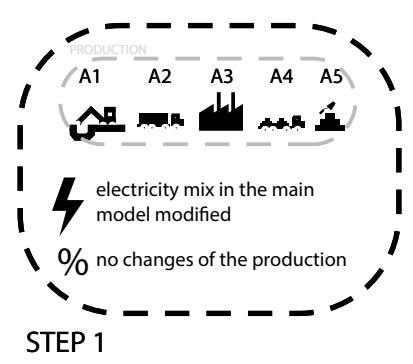

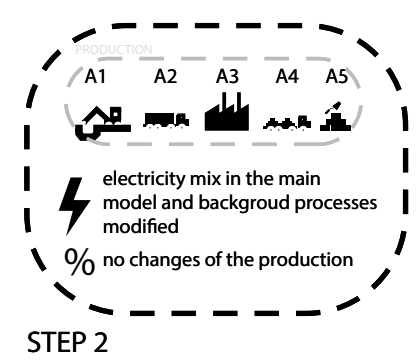

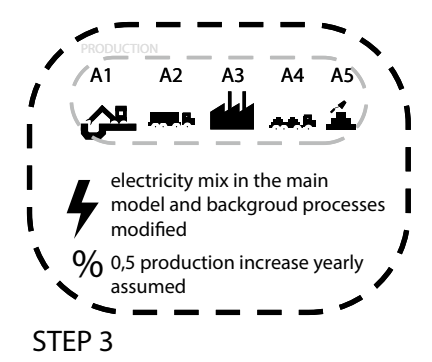


specific moment in the production phase, whereas the embodied energy/emissions includes the production phases (module A1-A5), maintenance (B4), and the end-of-life (EoL) phases (module C1-C4) according to EN 15804 (CEN 2012). The building materials and components are amortized within their reference service life (RSL), and the building should be amortized within the observed reference service period (RSP). The definitions of the building reference service period (RSP) and the reference service life (RSL) of the components are thus of great importance for defining the residual value of a building. These values can vary depending on the database of their source (Rauf and Crawford 2015). They are influenced by different parameters, e.g., the indoor and outdoor environments, the predicted maintenance, and the design of the product (Grant and Ries 2013; Grant et al. 2014; Dixit 2019).

In the presented case study, the residual-value calculation is simplified, because the aim of the study was to evaluate how the electricity-mix modification can influence the residual value of the building and to see if the differences can influence the decisions made about the future refurbishment measures. Only the production phases (A1 to A3 according to EN 15978) were used for the calculation of the residual value. The RSP of the building is 60 years. For the determination of the RSL of the individual components, the German BNB database was used. According to this database, none of the major components need to be replaced within the RSP of the building since their RSL is higher than 50 years, and therefore it was assumed that their amortization time is the same as the RSP (Bbsr 2011). The regular repainting of the walls has a negligible impact on the GHG emissions and was therefore not included in the residual value calculation of the whole building.

\section{Results}

This section presents the results of the GHG emissions and residual values for our case study, i.e., the apartment building dating from 1970 . The first subsection shows the

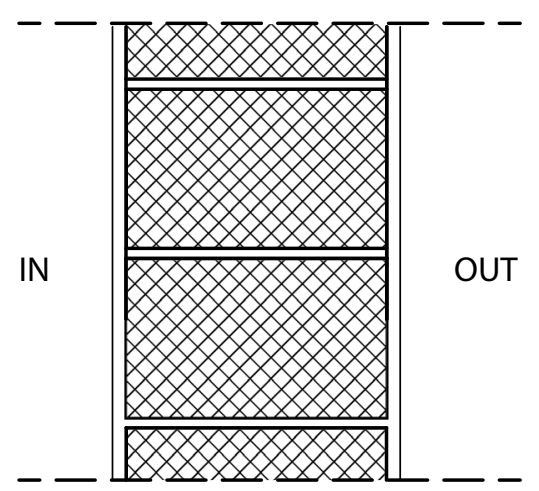

Fig. 6 Cross-section of the external wall remodelling approach for the individual components, and this is illustrated using the external wall as an example. This approach was also performed on all the other components of the building. The results for the other components are available in the Appendix. The purpose is to illustrate how the environmental impacts change when the electricity mixes from the production time of the existing materials are used for the calculation. Furthermore, datasets are also remodelled with future energy mixes, with the aim of investigating how the influence of the electricity mix will behave over time. In the next step, the difference in the results is shown for all the remaining components of the building. Finally, based on the previous results, the residual value of the building before refurbishment was calculated using different electricity mixes and the difference in the results was then analyzed.

\subsection{Remodelling of the external wall}

The external wall of our building (Fig. 6) is composed of the structural part, which is built from concrete blocks with adhesive mortar in the joints and a finishing layer (see Table 2). Base plaster is used on the inside, with a waterbased paint, and there is a cover coat on the outside.

Each individual dataset used in the external wall of the case study was remodelled according to the described methodology. When observing the results (see Table 3 and Fig. 7) after step 1 for the actual electricity mix (2020), it would appear that the contribution of the electricity mix to the total GHG emissions is relatively small in the case of some materials. For the concrete block, paint and the adhesive mortar, this value is between 0.7 and $1.1 \%$. The GHG emissions of the electricity mix are higher in the cases of the base plaster and the cover coat, at 5.2 and $12.9 \%$, respectively. In step 1 , however, the electricity mixes are modified only in the main process and not in all the sub-processes that are included in the main process. Although this approach is often applied in practice, it does not give realistic results, since it neglects the contribution of the electricity mix in the subprocesses that can substantially contribute to the final result. In step 2 , after the

Table 2 Exterior wall composition and basic data of the components

\begin{tabular}{llll}
\hline Exterior wall $1 \mathrm{~m}^{2}$ & & & \\
\hline & Thickness $(\mathrm{cm})$ & Volume $\left(\mathrm{m}^{3}\right)$ & Mass $(\mathrm{kg})$ \\
\hline Cover coat & 0.015 & 0.029 & 28 \\
Concrete brick & 0.29 & 0.275 & 440 \\
Adhesive mortar & $/$ & 0.015 & 30.45 \\
Base plaster & 0.015 & 0.015 & 24 \\
Alkyd paint & $/$ & $/$ & 0.28
\end{tabular}


Table 3 Relative contribution of the electricity mix towards the total GHG emission of materials calculated with electricity mixes for different periods and corresponding production efficiencies

\begin{tabular}{|c|c|c|c|c|c|c|c|c|c|c|c|c|}
\hline & \multicolumn{3}{|l|}{1970} & \multicolumn{3}{|l|}{2020} & \multicolumn{3}{|c|}{$2050 \mathrm{ECS}$} & \multicolumn{3}{|c|}{2050 NECP } \\
\hline & Step 1 & Step 2 & Step 3 & Step 1 & Step 2 & Step 3 & Step 1 & Step 2 & Step 3 & Step 1 & Step 2 & Step 3 \\
\hline Concrete block & $1.1 \%$ & $10.2 \%$ & $12.4 \%$ & $0.7 \%$ & $6.5 \%$ & $6.5 \%$ & $0.6 \%$ & $5.5 \%$ & $4.7 \%$ & $0.1 \%$ & $0.6 \%$ & $0.5 \%$ \\
\hline Adhesive mortar & $1.7 \%$ & $15.1 \%$ & $18.2 \%$ & $1.0 \%$ & $9.8 \%$ & $9.8 \%$ & $0.9 \%$ & $8.5 \%$ & $7.3 \%$ & $0.1 \%$ & $1.0 \%$ & $0.8 \%$ \\
\hline Base plaster & $8.2 \%$ & $14.5 \%$ & $17.5 \%$ & $5.2 \%$ & $9.4 \%$ & $9.4 \%$ & $4.4 \%$ & $8.1 \%$ & $7.0 \%$ & $0.5 \%$ & $0.9 \%$ & $0.8 \%$ \\
\hline Cover coat & $19.5 \%$ & $31.4 \%$ & $36.4 \%$ & $12.8 \%$ & $21.5 \%$ & $21.5 \%$ & $11.1 \%$ & $19.0 \%$ & $16.7 \%$ & $1.3 \%$ & $2.4 \%$ & $2.1 \%$ \\
\hline Paint & $1.7 \%$ & $7.5 \%$ & $9.2 \%$ & $1.1 \%$ & $4.7 \%$ & $4.7 \%$ & $0.9 \%$ & $3.9 \%$ & $3.3 \%$ & $0.1 \%$ & $0.4 \%$ & $0.4 \%$ \\
\hline
\end{tabular}

sub-datasets have been remodelled according to the substitution criterion, the relative contribution of the electricity mix increases, as illustrated in Fig. 7, since now also the GHG emissions of the electricity mix of the sub-databases were isolated and exchanged with the reference-year electricity mix. The relative contribution of the electricity to the total GHG emissions is 67.3 and $80.9 \%$ higher for the cover coat and base plaster, respectively. For the paint, adhesive mortar and concrete block, these contributions are even 4.4 to 9.4 times higher than in step 1 . They contribute from 4.8 to $21.5 \%$ to the total GHG emissions.

The objective of the study was to see if the remodelling of the datasets with the electricity mixes used in the past can influence the result. After the substitution of the current electricity mix with the 1970 electricity mix, the relative contribution of the electricity mix to the total GHG emission increases. The relative contribution after step 2 is between 7.5 and $31.4 \%$, which is on average $54.0 \%$ more than in 2020 . If the production efficiency is also considered (step 3 ), the relative contribution of the electricity mix is between 9.1 and $36.4 \%$. The total emissions increase by between 3.2 and $14.1 \%$ after step 2 and between 5.1 and $23.1 \%$ after step 3, as illustrated in Fig. 7. The increase in the total emissions is higher if the electricity mix of a single material contributes a lot to the total emissions. Therefore, the increase of the total emission is

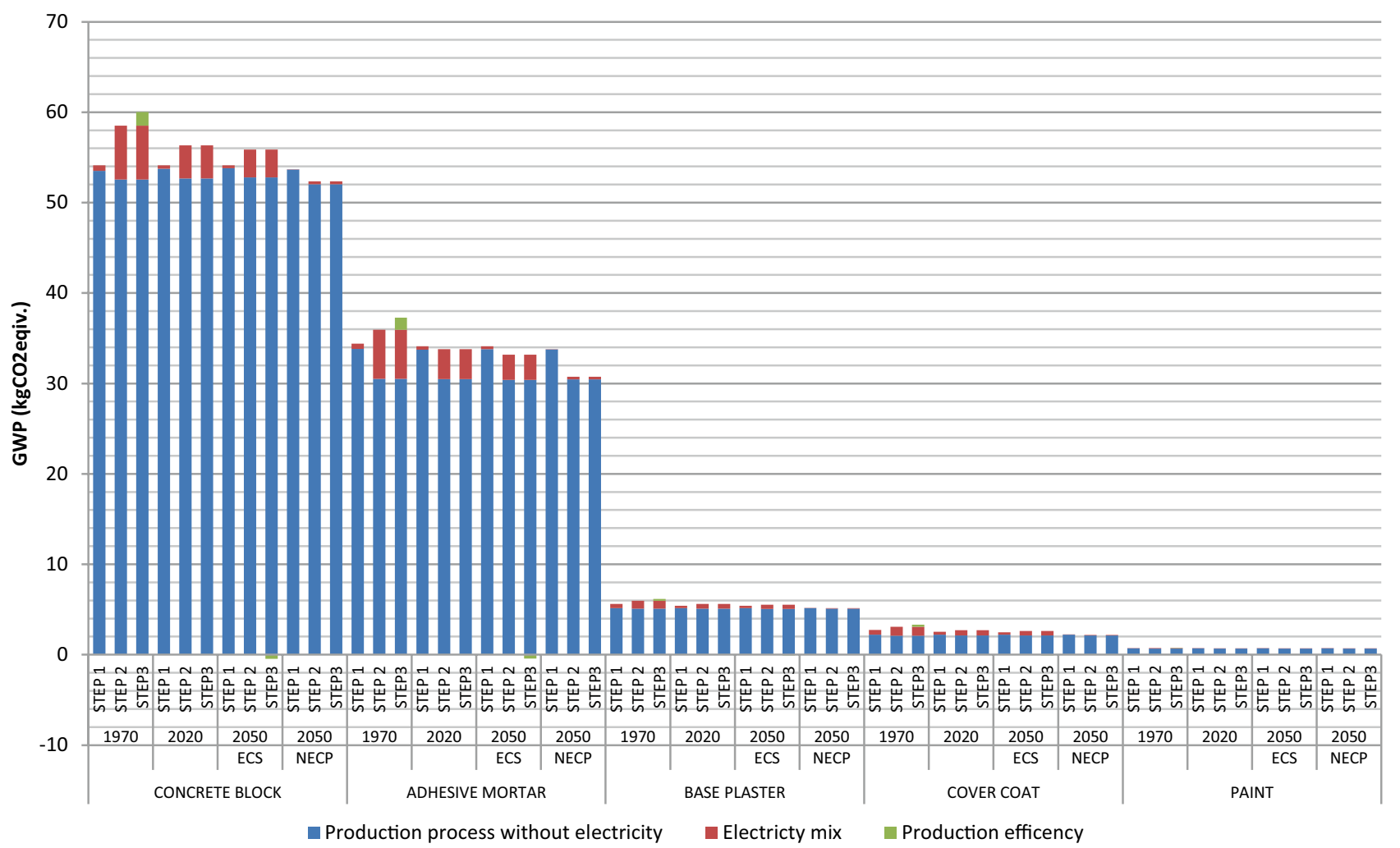

Fig. 7 Calculated GHG emissions of $1 \mathrm{~m}^{2}$ of outer wall from materials according to the new remodelling approach 
the lowest in the case of paint and the highest in the case of the cover coat.

In addition, we also remodelled the datasets with future electricity mixes (scenario ECS and NECPs) to compare how they contribute to changes in the total emissions in the future. The scenario ECS foresees an electricity mix that is similar to the current electricity mix. The relative share of the electricity mix in the total emissions is, on average, $15 \%$ lower for individual materials after step 2 and $25.0 \%$ lower if the production efficiency is also included (step 3). The total emissions decrease by between 0.8 and $2.9 \%$ for step 2 and between 1.4 and $5.7 \%$ for step 3 . In the case of the scenario $2050 \mathrm{NECP}$, which foresees an almost completely decarbonized electricity mix in the future, the contribution of the electricity mix to the total emissions decreases substantially. The relative share of the electricity mix towards the total emissions is, on average, $90.0 \%$ lower for individual materials (between 0.4 and $2.4 \%$ ) after step 2 and $91.5 \%$ lower (between 0.4 and $2.1 \%$ ) if the production efficiency is also included (step 3). The total emissions decrease by between 4.0 and $19.5 \%$ for step 2 and 4.1 and 19.8 for step 3 .

\subsection{Construction components}

The calculation procedure according to the new methodology was subsequently performed for other construction components of the building. The results after step 1 for the actual electricity mix (2020) show (see Table 4) that the contribution of the electricity mix to the total GHG emissions is between $0.7 \%$ in the case of the foundation up to $9.8 \%$ in the case of the roof. After further modification of the electricity mix of all the relevant sub-dataset that applies, according to the declared substitution rules (step 2), the contribution of the electricity mix to the total emissions grows from 8.0 to $13.9 \%$.

Furthermore, if we are substituting the electricity mix with the energy mix of 1970 , the relative contribution of the electricity mix increases by $50 \%$ on average. In the first step (step 1), the relative share of the GHG emissions caused by the electricity mix is in the range between 1.1 and $2.9 \%$ for the foundation, outer walls, and inner walls. In the case of the windows and roof, the contribution of the electricity mix to the total GHG emissions is higher, i.e., 8.6 and $15.2 \%$. With the engagement of the procedure in step 2 , the relative contribution of the electricity mix to the total emissions rises from 12.75 to $20.83 \%$. In addition, with the introduction of the production efficiency (step 3), the relative contribution of the electricity mix rises to values between 15.1 and $24.8 \%$. As illustrated in Fig. 8, the total emissions in step 2 increase between 5.0 and $9.0 \%$. If an additional decrease of the production efficiency is considered (step 3 ), the total emissions increase to between 8.3 and 14.7. Again, the increase of the total emissions is higher if the electricity mix contributes in a greater amount to the total emissions. The changes in the total GHG emission are not significant, but they should not be neglected in the case they are used for calculating the residual value of a material or a component.

The relative contribution of the electricity mix to the total emissions is reduced when the modified electricity mix has a lower environmental impact compared to the current electricity mix. This is the case for the two presented future scenarios. In the 2050 ECP scenario, the relative contribution of the electricity mix to the total GHG emissions is similar to the case of the current electricity mix. In step 2 , the relative share in the total emissions is on average $14 \%$ lower (between 12.5 and 20.8\%). If an additional increase of the production efficiency is considered, the relative contribution decreases by $25.7 \%$ (the relative share is between 15.1 and $24.8 \%$ ). The decrease of the total GHG emissions is between 1.2 and 2.2 for step 2. If the increase of the production efficiency is considered, the total emissions decrease between 2.3 and $3.9 \%$. For the 2050 NECPs scenario, the decrease of the environmental emissions associated with the electrify mix is considerably higher.

In step 2, the relative share of the total emissions is between 0.8 and $2.1 \%$. If a further increase of the production efficiency is considered, the relative contribution is even lower, between 0.7 and $1.8 \%$ to the total GHG emissions. In this case, the electricity mix is almost decarbonized;

Table 4 Relative contribution of the electricity mix to the total GWP emission of components calculated with electricity mixes for different periods and corresponding production efficiencies

\begin{tabular}{|c|c|c|c|c|c|c|c|c|c|c|c|c|}
\hline & \multicolumn{3}{|l|}{1970} & \multicolumn{3}{|l|}{2020} & \multicolumn{3}{|c|}{$2050 \mathrm{ECS}$} & \multicolumn{3}{|c|}{2050 NECP } \\
\hline & Step 1 & Step 2 & Step 3 & Step 1 & Step 2 & Step 3 & Step 1 & Step 2 & Step 3 & Step 1 & Step 2 & Step 3 \\
\hline Outer wall & $2.3 \%$ & $12.7 \%$ & $15.4 \%$ & $1.4 \%$ & $8.2 \%$ & $8.2 \%$ & $1.2 \%$ & $7.0 \%$ & $6.0 \%$ & $0.1 \%$ & $0.8 \%$ & $0.7 \%$ \\
\hline Foundation/Slab & $1.1 \%$ & $16.2 \%$ & $19.4 \%$ & $0.7 \%$ & $10.5 \%$ & $10.5 \%$ & $0.6 \%$ & $9.1 \%$ & $7.8 \%$ & $0.1 \%$ & $1.1 \%$ & $0.9 \%$ \\
\hline Inner wall & $2.9 \%$ & $12.5 \%$ & $15.1 \%$ & $1.8 \%$ & $8.0 \%$ & $8.0 \%$ & $1.5 \%$ & $6.9 \%$ & $5.9 \%$ & $0.2 \%$ & $0.8 \%$ & $0.7 \%$ \\
\hline Window & $8.6 \%$ & $20.8 \%$ & $24.8 \%$ & $5.4 \%$ & $13.9 \%$ & $13.9 \%$ & $4.6 \%$ & $12.0 \%$ & $10.4 \%$ & $0.7 \%$ & $2.1 \%$ & $1.8 \%$ \\
\hline Roof & $15.2 \%$ & $20.2 \%$ & $24.1 \%$ & $9.8 \%$ & $13.4 \%$ & $13.4 \%$ & $8.5 \%$ & $11.6 \%$ & $10.0 \%$ & $1.0 \%$ & $1.4 \%$ & $1.2 \%$ \\
\hline
\end{tabular}




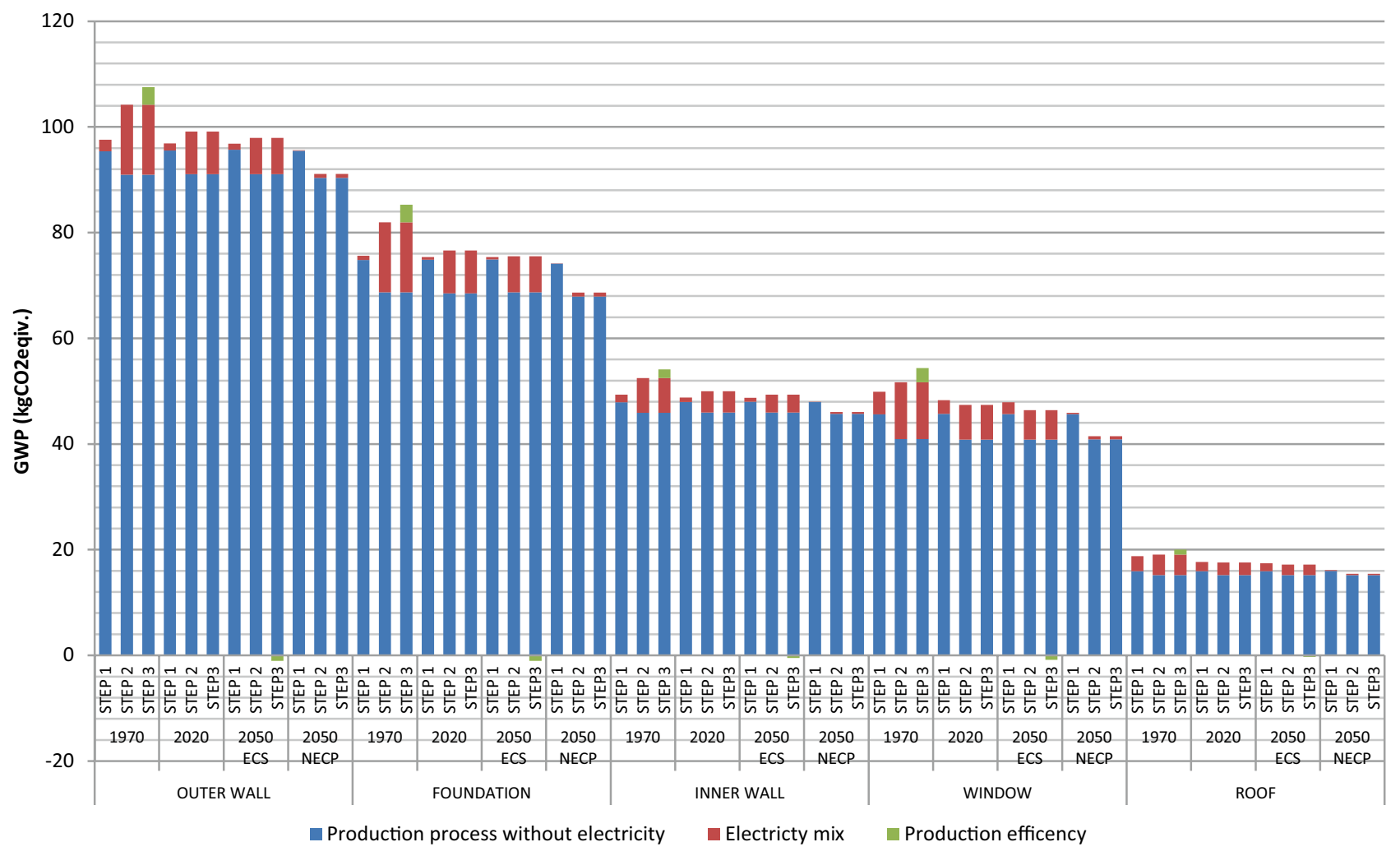

Fig. 8 GHG emissions for $1 \mathrm{~m}^{2}$ of all construction components of the building

therefore, it also does not contribute a lot to the total emissions. The decrease in GHG emission lies between 7.8 and $12.5 \%$ for step 2 and between 8.0 and $12.7 \%$ for step 3 .

\subsection{Residual value of the building}

In the continuation of the article, the results for the residual value are presented, calculated for our case study of the selected building using different data for the electricity mixes. The results show that for the selected case study, the residual value is $9.7 \%$ higher if the time-corresponding datasets for the electricity mix are used instead of the electricity mix from today. Assuming that the electricity in 1970 was more efficient (for example similar to the electricity mixes 2050 ECS and $2050 \mathrm{NECP}$ ), this would mean that the residual value observed at a certain point in time would be lower. If calculating with the 2050 ECS electricity mix, the residual value is $2.5 \%$ lower, while in the case of an almost-decarbonized electricity mix (2050 NECP), the residual value would be $9.8 \%$ lower. When we are dealing with residual value, the relative differences in impacts are the same. The absolute differences of the impacts calculated with different electricity mixes, however, are decreasing, the more we are approaching the end of the RSL. Therefore, the differences in result are greater if the residual value is high and become less important when we are approaching the end of the RSL of the component or the building (Fig. 9).

\section{Discussion}

The contribution of the electricity mix to the total GHG emissions of materials and components can be falsely interpreted as minor if just the contribution of the electricity mix of the final process (the main datasets) is observed (Roux et al. 2016). It is important that the electricity mixes are considered also in all the sub-processes (sub-datasets) to obtain a realistic impression about the impact of the electricity mix on the total environmental emissions. Technically, this means that the existing datasets must be provided with a structure that enables the modification and adjustment of certain inputs. In this sense, the u-so way of modelling as used, for example, in Ecoinvent, has a clear advantage over the datasets modelled as aggregated (agg) datasets. Although the calculation with aggregated datasets is faster and the files are smaller, this method does not provide a clear insight for the inputs and thus also for the remodelling of the datasets (Espinoza et al. 2000).

In the presented study, the contribution of the electricity mix to the total emissions was as high as $20 \%$. It is therefore a very important parameter when calculating the total 
Fig. 9 Residual values of our case study, the selected building, calculated with different electricity mixes

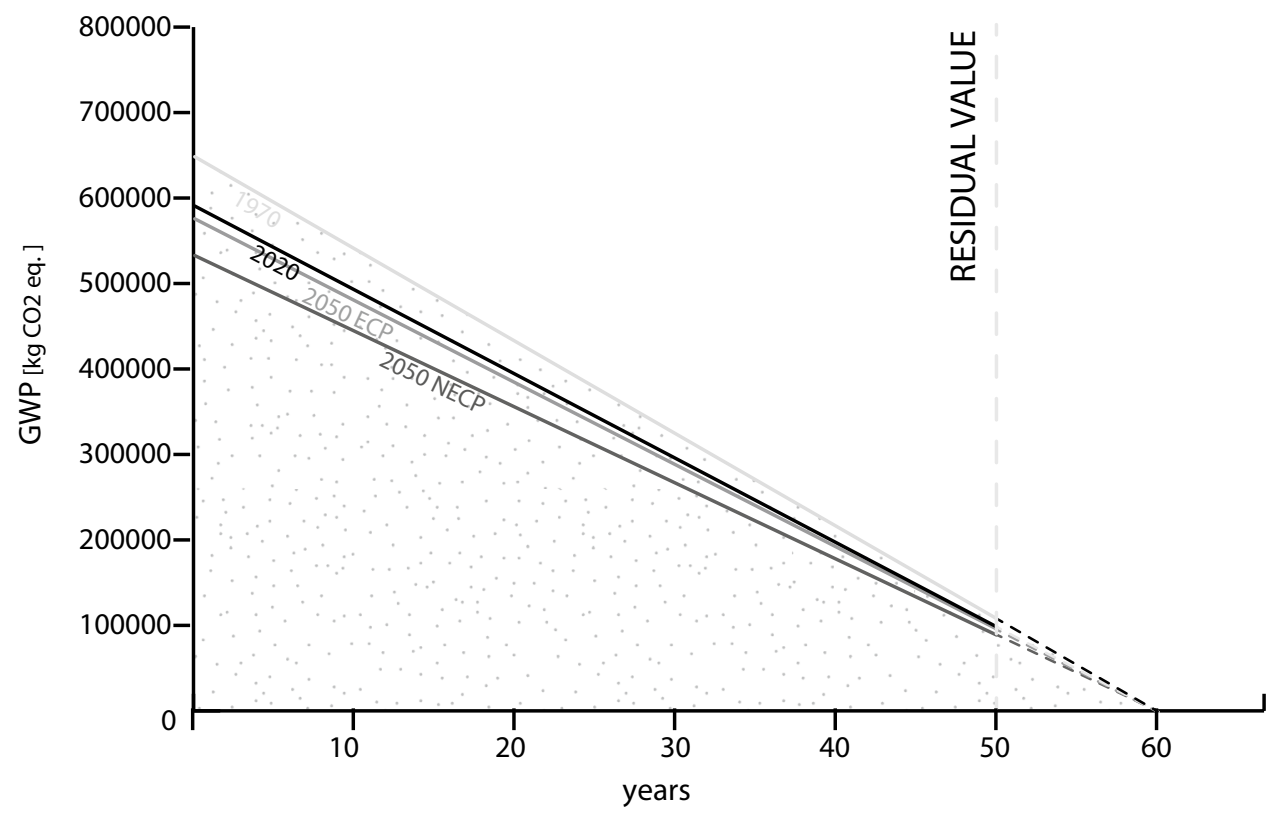

environmental emissions of the materials and components, as also shown in other studies (Pomponi and Moncaster 2016; Roux et al. 2016; Kiss and Szalay 2020). This parameter, however, is subject to major changes over time. We have observed that in many cases, the electricity mix for the future is modified time-dependently, but remodelling the data for the past, as presented in our case is an innovation. The environmental impacts of electricity mixes have generally been greater in the past than they are today. In our study, we are assuming that the production processes remained similar and that only the electricity mix and the efficiency of the electricity use have changed over time, so, consequently, the environmental impacts of the materials and components manufactured in the past were also greater and the relative contribution of the electricity mix on the total GHG emissions was also higher at that time. In the presented case, the total emissions for individual building components were between 5.0 and $9.0 \%$ higher, if the current electricity mix was substituted with the electricity mix of 1970. If the production efficiency decrease was also to be considered, the difference in total emissions is between 8.3 and $14.7 \%$. In the presented study, we have worked with the assumption that attempts to replicate the reality of the situation, while at the same time introducing uncertainty into the calculation, as also discussed by (Van De Moortel et al. 2019).

On the other hand, the current regulation is streaming towards decarbonisation and minimization of the environmental footprint of the electricity mix in the future (EC 2020). The environmental emissions of the future electricity mixes will be reduced and will become more or less negligible, which opens up further areas of investigation
(Pomponi and Moncaster 2016; Roux et al. 2016; Kiss and Szalay 2020). This was also observed in the presented study for the GHG emissions. It is assumed that the future electricity mixes perform better in all the environmental categories recommended by EN 15804. The exception is the abiotic depletion of elements that could become a major burden in the future in the case of the increased share of photovoltaic generated electricity (Turconi et al. 2013). This assumption, however, is based on calculations with current datasets that reflect the technological state of the art. This problem could be resolved with greener technologies in the future. Establishing what the meaningful differences between the compared electricity mixes should be in order that replacing them will be worthwhile is a research task for the future.

The differences in results can be substantial, as presented here, and it is thus recommended that the remodelling of the datasets is performed if we intend to use the data for the calculation of the former impacts of the manufacturing of existing buildings and also plan future refurbishment measures based on it. In the study of Kohler et al. (2010) it is indicated that the residual value is an indicator of building aging and can therefore be used as a criterion for building preservation or demolishment. In addition to this, the residual value gives information about the amortization of the materials or components and this can be used for a decision about their preservation and reuse or their discarding. The findings showed that the relative differences in the results for the phases A1-A3 were also up to $10 \%$. The absolute differences in the results are dependent on the amortization time. Consequently, an unprecise determination of the residual value could lead to premature refurbishments, demolition and discarding building materials or components to early if the 
decision would be made only based on the residual value and if the electricity mix of the reference year of the construction would have a higher impact than the current electricity mix. It also makes a difference whether the product is near the end of the depreciation period, since the absolute differences are relatively small towards the end of the amortization period, and therefore, the modification of the electricity mix does not influence the results to any great extent, compared to the beginning of the amortization period. The scope of the study is the production phase; however, it does not include the embodied impacts of the maintenance activities. If these impacts were to be included, the substituted materials would be at different levels of amortization, and therefore, the absolute differences could be influenced by the electricity mix. These aspects can also be part of future research.

\section{Conclusions}

The present study confirmed that the electricity mixes used in the production of buildings can significantly influence the calculated values for the environmental impacts of buildings in need of refurbishment. Our results from calculations in the case of an apartment building showed that the contribution of emissions from the electricity mixes of different time periods could be as high as $20 \%$ in the context of individual materials. It must be emphasized that the contribution of the electricity mix to the total GHG emissions will need to be evaluated along the entire chain of datasets and subdatasets, since the modification of the electricity mix only in the original dataset (and not in sub-datasets) could lead to a false estimation. It is assumed that the embodied environmental impacts of the past are even higher because the production was less efficient, and therefore, more electricity was needed for the production of the materials. Individual changes in production efficiency are usually the internal data of the manufacturer, and this is not commonly disclosed or is not even known or recorded; thus, only the general value (i.e., $0.5 \%$ per year) could be used in the calculations. In the presented case, we have shown that the total GHG emissions of individual materials and components can increase by 5.0 and $14.7 \%$ or decrease by between 1.2 and $12.7 \%$, depending on the emissions of the used electricity mix and the projected change of the production efficiency.

In addition, it was established that the time-dependent modifications in the electricity mix can also have a strong impact on the residual value of any building. The relative difference in the presented case was in the range of $10 \%$, but the absolute values decreased towards the end of the amortization periods for individual materials and components. Decisions about the potential refurbishment or demolishing of a building, time of maintenance actions, or the handling of individual materials and components based on the residual value require a precise and realistic calculation with the correct data at the point of time. The differences in results are not neglectable and can potentially lead to premature and incorrect actions (e.g., the building being renovated too early, which elements are worth preserving from the environmental perspective, etc.).

An analysis of the results obtained in the present study revealed that parameters which are usually subject to a major change during the service life of the building need to be included in life cycle calculations with the correct data at the point of time. This means that all time-dependent data sets related to the electricity mix and productivity efficiency are used correctly in the assessment (for individual time periods). This was clearly illustrated in the calculation of the residual value of the selected building before the refurbishment. In doing so, however, these analyses also provide valuable insights that can be applied for a variety of purposes for each product with a long life span. Ideally, the dynamic inventory data should also be coupled with dynamic characterization factors to obtain a fully dynamic LCA, but the dynamic characterization factors for different environmental categories are still under development and this issue should thus be a part of future research.

The present LCA study is focused into the production stage and not on the use and end-of-life (EoL) stages. The specific parameters of these stages will be covered in our future study to evaluate the environmental impacts of various refurbishment measures.

Supplementary Information The online version contains supplementary material available at https://doi.org/10.1007/s11367-021-01920-2.

Acknowledgements The authors would like to thank Dr. Roman Kunič for his support. Although no longer among us, he will remain a valuable member of our team. The authors would also like to thank Marcella Ruschi Mendes Saade for her valuable inputs. We appreciate the remarks and advice given by the anonymous reviewers, which helped to improve the paper substantially.

Author contribution The contribution is financially supported by the Slovenian Research Agency (research core funding no. P2-0273 and the funding of young researcher no. 38191).

Funding Open access funding provided by Graz University of Technology.

Open Access This article is licensed under a Creative Commons Attribution 4.0 International License, which permits use, sharing, adaptation, distribution and reproduction in any medium or format, as long as you give appropriate credit to the original author(s) and the source, provide a link to the Creative Commons licence, and indicate if changes were made. The images or other third party material in this article are included in the article's Creative Commons licence, unless indicated otherwise in a credit line to the material. If material is not included in the article's Creative Commons licence and your intended use is not permitted by statutory regulation or exceeds the permitted use, you will need to obtain permission directly from the copyright holder. To view a copy of this licence, visit http://creativecommons.org/licenses/by/4.0/. 


\section{References}

Agostino DD, Zangheri P, Castellazzi L (2017) Towards nearly zero energy buildings in europe : a focus on retrofit in non-residential buildings. 2020:https://doi.org/10.3390/en10010117

Anand CK, Amor B (2017) Recent developments, future challenges and new research directions in LCA of buildings: a critical review. Renew Sustain Energy Rev 67:408-416. https://doi.org/10.1016/j. rser.2016.09.058

Assiego de Larriva R, Calleja Rodriguez G, Cejudo Lopez JM, et al (2014) A decision-making LCA for energy refurbishment of buildings: conditions of comfort. Energy Build 70:333-342. https://doi.org/10.1016/j.enbuild.2013.11.049

Ballarini I, Corgnati SP, Corrado V (2014) Use of reference buildings to assess the energy saving potentials of the residential building stock: the experience of TABULA project. Energy Policy 68:273284. https://doi.org/10.1016/j.enpol.2014.01.027

Barros MV, Salvador R, Piekarski CM et al (2020) Life cycle assessment of electricity generation: a review of the characteristics of existing literature. Int J Life Cycle Assess 25:36-54. https://doi. org/10.1007/s11367-019-01652-4

Bbsr (2011) Nutzungsdauern von Bauteilen für Lebenszyklusanalysen nach Bewertungssystem Nachhaltiges Bauen (BNB). https://www. nachhaltigesbauen.de/fileadmin/pdf/baustoff_gebauededaten/ BNB Nutzungsdauern_von_Bauteilen_2017-02-24.pdf. Accessed 9 Apr 2020

CEN (2011) EN 15978:2011 Sustainability of construction works Assessment of environmental performance of buildings - Calculation method

CEN (2012) EN 15804:2012 + A2:2019 - Sustainability of construction works - Environmental product declarations - core rules for the product category of construction products

Collinge WO, Landis AE, Jones AK, et al (2013) Dynamic life cycle assessment: framework and application to an institutional building. 538-552. https://doi.org/10.1007/s11367-012-0528-2

Corrado V, Ballarini I (2016) Refurbishment trends of the residential building stock: analysis of a regional pilot case in Italy. Energy Build 132:91-106. https://doi.org/10.1016/j.enbuild.2016.06.022

Dixit MK (2019) Life cycle recurrent embodied energy calculation of buildings: a review. J Clean Prod 209:731-754. https://doi.org/10. 1016/j.jclepro.2018.10.230

EC (2020) European Green Deal Call. In: Eur. Comm. file:///C:/ Users/mlsf/Downloads/European_Green_Deal_Call___1_billion_investment_to_boost_the_green_and_digital_transition. pdf. Accessed 24 Apr 2020

Espinoza GR, Aguilera MH, Irarrázaval LMJ, Bosch OE (2000) Ruptura traumática de la aorta torácica y tratamiento no-operatorio de lesión esplénica concomitante. Caso clínico

European Commission (2020) National energy and climate plans (NECPs). https://ec.europa.eu/energy/topics/energy-strategy/ national-energy-climate-plans_en. Accessed 15 May 2020

Fořt J, Beran P, Pavlík Z, Černý R (2018) Complex assessment of reconstruction works on an institutional building: a case study. J Clean Prod 202:871-882. https://doi.org/10.1016/j.jclepro. 2018.08.197

Giuda GM Di, Villa V, Piantanida P (2015) \{BIM $\}$ and Energy efficient retrofitting in school buildings. Energy Procedia 78:10451050. https://doi.org/10.1016/j.egypro.2015.11.066

Grant A, Ries R (2013) Impact of building service life models on life cycle assessment. Build Res Inf 41:168-186. https://doi.org/10. 1080/09613218.2012.730735

Grant A, Ries R, Kibert C (2014) Life Cycle Assessment and Service Life Prediction A Case Study of Building Envelope Materials. 18. https://doi.org/10.1111/jiec.12089
Häkkinen T (2012) Systematic method for the sustainability analysis of refurbishment concepts of exterior walls 37:783-790. https:// doi.org/10.1016/j.conbuildmat.2012.07.084

Heijungs R, Settanni E, Guinée J (2013) Toward a computational structure for life cycle sustainability analysis: unifying LCA and LCC. Int J Life Cycle Assess 18:1722-1733. https://doi.org/10. 1007/s11367-012-0461-4

IEA and UNEP (2019) 2019 Global Status Report for Buildings and Construction

IPCC (2018) Global Warming of $1.5^{\circ} \mathrm{C}$. IPCC Special Report 1.5 Summary for Policymakers

Kiss B, Szalay Z (2020) Modular approach to multi-objective environmental optimization of buildings. Autom Constr 111.https:// doi.org/10.1016/j.autcon.2019.103044

Kohler N, König H, Kreissig J, Lützkendorf T (2010) A life cycle approach to buildings. DETAIL

Kono J, Ostermeyer Y, Wallbaum H (2017) The trends of hourly carbon emission factors in Germany and investigation on relevant consumption patterns for its application. Int J Life Cycle Assess 22:1493-1501. https://doi.org/10.1007/s11367-017-1277-z

Martínez-Rocamora A, Solís-Guzmán J, Marrero M (2016) LCA databases focused on construction materials: a review. Renew Sustain Energy Rev 58:565-573. https://doi.org/10.1016/j.rser. 2015.12.243

Mastrucci A, Marvuglia A, Leopold U, Benetto E (2017) Life Cycle Assessment of building stocks from urban to transnational scales: A review. Renew Sustain Energy Rev 74:316-332. https://doi.org/10.1016/j.rser.2017.02.060

Oregi X, Hernandez P, Gazulla C, Isasa M (2015) Integrating simplified and full life cycle approaches in decision making for building energy refurbishment: benefits and Barriers. Buildings 5:354-380. https://doi.org/10.3390/buildings5020354

Oregi X, Hernandez P, Hernandez R (2017) Analysis of life-cycle boundaries for environmental and economic assessment of building energy refurbishment projects PHASE. Energy Build 136:12-25. https://doi.org/10.1016/j.enbuild.2016.11.057

Ortiz J, Fonseca A, Salom J, Garrido N (2016) Cost-effective analysis for selecting energy efficiency measures for refurbishment of residential buildings in Catalonia. Energy Build 128:442-457. https://doi.org/10.1016/j.enbuild.2016.06.059

Passer A, Ouellet-plamondon C, Kenneally P et al (2016) The impact of future scenarios on building refurbishment strategies towards plus energy buildings. Energy Build 124:153-https://doi.org/10. 1016/j.enbuild.2016.04.008

Pomponi F, Farr ERP, Piroozfar P, Gates JR (2015) Façade refurbishment of existing of fi ce buildings: do conventional energy-saving interventions always work ? J Build Eng 3:135-143. https://doi.org/ 10.1016/j.jobe.2015.07.003

Pomponi F, Moncaster A (2016) Embodied carbon mitigation and reduction in the built environment-what does the evidence say? J Environ Manage 181:687-700. https://doi.org/10.1016/j.jenvman. 2016.08.036

Potrč Obrecht T, Kunič R, Jordan S, Legat A (2019) Roles of the reference service life (RSL) of buildings and the RSL of building components in the environmental impacts of buildings. IOP Conf Ser Earth Environ Sci 323. https://doi.org/10.1088/1755-1315/ 323/1/012146

Rauf A, Crawford RH (2015) Building service life and its effect on the life cycle embodied energy of buildings. Energy 79:140-148. https://doi.org/10.1016/j.energy.2014.10.093

Röck M, Ruschi Mendes Saade M, Balouktsi M et al (2019) Embodied GHG emissions of buildings - the hidden challenge for effective climate change mitigation. Appl Energy 258:114107. https://doi. org/10.1016/j.apenergy.2019.114107 
Rodrigues F, Matos R, Rodrigues H et al (2018) Building Life Cycle applied to refurbishment of a traditional building from Oporto, Portugal. J Build Eng. https://doi.org/10.1016/j.jobe.2018.01.010

Roux C, Schalbart P, Assoumou E, Peuportier B (2016) Integrating climate change and energy mix scenarios in LCA of buildings and districts. Appl Energy 184:619-629. https://doi.org/10.1016/j. apenergy.2016.10.043

Ruud S, Östman L, Orädd P (2016) Energy savings for a wood based modular pre-fabricated façade refurbishment system compared to other measures. Energy Procedia 96:768-778. https://doi.org/10. 1016/j.egypro.2016.09.139

Saade MRM, Gomes V, da Silva MG, Ugaya CML, Lasvaux S, Passer A, Habert G (2019) Investigating transparency regarding ecoinvent users' system model choices. Int J Life Cycle Assess 24(1): $1-5$

Severin L (2018) SIA2032: Graue Energie - Ökobilanzierung für die Erstellung von Gebäuden. 1-37

SI-STAT SI-STAT. http://pxweb.stat.si/pxweb/dialog/statfile2.asp

Slovenian Ministry of Infrastructure (2017) The energy concept of Slovenia. https://www.energetika-portal.si/fileadmin/dokumenti/ publikacije/eks/razprava_jun_2017/eks_priloga1.pdf

Stazi F, Vegliò A, Di C, Munafò P (2012) Retrofitting using a dynamic envelope to ensure thermal comfort, energy savings and low environmental impact in Mediterranean climates. Energy Build 54:350-362. https://doi.org/10.1016/j.enbuild.2012.07.020

Su S, Li X, Zhu Y, Lin B (2017) Dynamic LCA framework for environmental impact assessment of buildings. Energy Build 149:310 320. https://doi.org/10.1016/j.enbuild.2017.05.042

Turconi R, Boldrin A, Astrup T (2013) Life cycle assessment (LCA) of electricity generation technologies: overview, comparability and limitations. Renew Sustain Energy Rev 28:555-565. https://doi. org/10.1016/j.rser.2013.08.013

UN (2016) Paris Agreement. In: Int. Leg. Mater. https://unfccc.int/ process-and-meetings/the-paris-agreement/the-paris-agreement. Accessed 24 Apr 2020

UN Environment Programme (2018) UN Environment Annual Report

UNEP (2020) Sustainable buildings I UNEP - UN Environment Programme. In: UN Environ. https://www.unenvironment.org/ explore-topics/resource-efficiency/what-we-do/cities/sustainablebuildings. Accessed 10 Apr 2020

Van De Moortel E, Allacker K, De Troyer F et al (2019) Life cycle environmental impact of refurbishment of social housing IOP Conf Ser Earth Environ Sci 323.https://doi.org/10.1088/1755$1315 / 323 / 1 / 012013$

Vilches A, Garcia-martinez A, Sanchez-monta B (2017) Life cycle assessment (LCA) of building refurbishment : A literature review. 135:286-301. https://doi.org/10.1016/j.enbuild.2016.11.042

Wang L, Wang Y, Du H et al (2019) A comparative life-cycle assessment of hydro-, nuclear and wind power: a China study. Appl Energy 249:37-45. https://doi.org/10.1016/j.apenergy.2019.04. 099

Werner P, Bauer CJ, Steubing B et al (2016) The ecoinvent database version 3 (part I): overview and methodology. Int J Life Cycle Assess 21:1218-1230

Wu C, Xu B, Mao C, Li X (2017) Overview of bim maturity measurement tools. J Inf Technol Constr 22:34-62

Publisher's Note Springer Nature remains neutral with regard to jurisdictional claims in published maps and institutional affiliations.

\section{Authors and Affiliations}

\section{Tajda Potrč Obrecht ${ }^{1}\left[\right.$ - Sabina Jordan ${ }^{1} \cdot$ Andraž Legat $^{1} \cdot$ Alexander Passer $^{2}$}

1 Slovenian National Building and Civil Engineering Institute, Dimičeva 12, 1000 Ljubljana, Slovenia

2 Institute of Technology and Testing of Construction Materials, Working Group Sustainable Construction, Graz
University of Technology, Waagner-Biro Straße 100/XI, 8020 Graz, Austria 